\title{
ASSESSING CORPORATE SUSTAINABILITY WITH REPERTORY Grid Based Personal Construct Psychology
}

\author{
Henning BUNDTZEN \\ Kaposvár University, Doctoral School in Management and Organizational Sciences, \\ H-7400 Kaposvár, Guba Sándor u. 40.
}

\begin{abstract}
Corporate sustainability (CS) is becoming a key feature for preparing an organization for the future challenges of its competitive environment. It has expanded from corporate social responsibility (CSR) by adding the dimensions of ethical, environmental, economic and cultural responsibility whilst asking for a long-term perspective of sustainability for the aforementioned subjects. This paper summarizes the concept of corporate sustainability focusing on the most relevant topics of recent scientific literature. The findings are compared to the results of 61 repertory grid interviews to evaluate how far corporate sustainability is already carried into practical notion. It is tested whether this type of interview technique and the underlying theory of personal constructs allow a visualization of the CS status of an organization. In addition, this article gives a brief outlook on the interconnection of leadership, corporate culture and corporate sustainability.
\end{abstract}

Keywords: corporate sustainability, corporate social responsibility, repertory grid analysis, personal construct psychology

\section{INTRODUCTION}

Ecological and social responsibility are increasingly important topics in the business environment of today's operating corporations. Even corporate social responsibility is already difficult to comply with, it has been complemented by another important dimension (Engert et al., 2016). Firstly, it is important to define a common understanding about the term corporate sustainability. A wide definition is given by Dyllick and Hockerts: “... meeting the needs of a firm's direct and indirect stakeholders (such as shareholders, employees, clients, pressure groups, communities etc.), without compromising its ability to meet the needs of future stakeholders as well' (Dyllick and Hockerts, 2002). In this paper we follow the definitions made by Hahn, Aras and Crowther who included the dimension of societal influence, environmental impact, organizational culture and finance (Aras and Crowther, 2008) which corresponds mainly to the three principles: environmental integrity, social equity and economic prosperity defined by Hahn (Hahn and Figge, 2011).

Internally, leadership from a business perspective is the most important driver of CS. This is a proactive approach instead of reacting after bad press for example (Ashrafi et al., 2018). From the outside of a company a demand for sustainable business practices is driven by reputation, shifting customer preferences as well as legal requirements like legislation (Lozano, 2015). Nevertheless, organizations still have difficulties to put this 
necessity into practice (Ameer and Othman, 2011). In the first step corporate sustainability must become part of the business strategy to have a chance to be implemented in practice. The second challenge is to put it into operational practice of all the organizations' employees (Bonn and Fisher, 2011). The underlying question is always how this affects a company's performance, as the topic has to move from the idea that it is only a cost factor to a perspective that corporate sustainability can even improve an organization's performance (Sen and Bhattacharya, 2001) and is a must to secure the long term future of a company (Ameer and Othman, 2012).

It is crucial that internal motivations by leadership are commonly more proactive than any externally forced motivations. One internal motivation which is becoming increasingly important is attracting and retaining employees. Due to population changes, a lack of workers has evolved into a common problem (Epstein and Roy, 2001). Alongside corporate sustainability can improve the employee's commitment and motivation, it has a positive side effect. That way it can even be a key driver of the financial performance of a company (Lozano, 2015; Sen and Bhattacharya, 2001). Another advantage of incorporating $\mathrm{CS}$ is that it can boost innovation within an organization alongside a social trend and increase a product's quality while simultaneously even lower the economical footprint. Reduction of waste as an originally internal motivation can reduce costs on the other side (Lozano, 2013; Hahn et al., 2017).

External motivations or drivers can be for example to improve trust outside the company with stakeholders, like customers or suppliers, which coincides with the stakeholder centred definition made by Dyllicke and Hockerts. It can even go that far that an organization needs to earn a "license to operate" (Frankental, 2001). Anther external factor can be access to certain markets as an example. An improved customer satisfaction and an enhanced corporate and brand reputation are examples of external motivations linked to corporate sustainability as well (Dunphy et al., 2007).

Lozano did a comprehensive research on the relevance of the internal drivers and motivations that lead to an effective implementation of a corporate sustainability system linked to the business strategy of a company (Lozano, 2012). Some of the most frequent mentioned drivers of interviewed top-level managers highlighted proactive leadership, a business case, precautionary principles or the company's culture as internal drivers (Schaltegger and Lüdeke-Freund, 2012). As external drivers reputation, customer demands and legislation were highlighted by the executives (Lozano, 2013). Hahn tried to create a standard process to incorporate sustainability and corporate social responsibility into the management and leadership of a company (Hahn, 2012). Only if a sustainable approach and sustainable thinking are part of the company's vision and strategy, it can be lived on an operational level (Eweje, 2011). When getting empirical insights, though the topic is brought up leaving the interviewee thinking about sustainability, whilst before it might not have been of relevance for the organization's work ethics (Klettner et al., 2013).

\section{MATERIALS AND METHODS}

As a basis for this research 61 repertory grid structured interviews were carried out within an organization. The research object is a wholesale company in the consumer industry with approximately 500 employees of which 21 staff members are in leadership roles. The 
company is led by two general managers who, besides the founder, are also shareholders of the organization. The company has experienced 45 years of growth and accomplished 200 Mio. $€$ turnover in 2018. The forecast and current business development is positive with a turnover increase forecasted for 2019 and 2020. Overall, the organization is financially healthy, paying above standard pay scale. Employees have the possibility to invest into a shareholding company so that they directly participate in the success of the corporation. Fluctuation among employees is on a comparably low level. Recruitment of additional staff is still unproblematic and applicants state that they have been told about the great working atmosphere. Hence a high employer attractiveness is presumed.

The main objective of the research is to analyse the corporate culture and leadership culture of the organization by conducting repertory grid structured interviews with all 21 members of the management team and 40 employees throughout all departments of the organization. The employees were selected in proportion to the size of each department. The repertory grid technique originates from George Kelly's personal construct theory (Kelly, 1955). Kelly suggested in his theory that individuals continuously strive to make sense of their own world and their place within this world, just like scientists (Cassell et al., 2000). Within the scope of this research the theory is applied to an organization surrounding an individual. This means that an originally psychological theory on how people make sense of their own world is used to evaluate how employee make sense or judge the organization they are working for. Personal construct psychology (PSP) claims that individuals develop personal constructs or theories of themselves and their organization based on the sum of their experiences (Fransella et al., 2003). The conducted repertory grid interviews based on Kelly's theory of personal constructs allow furthermore an unbiased qualitative and quantitative method (Robertson, 2003) to evaluate which role sustainability plays in the company culture. The applied repertory grid technique asks the interviewed person to construe in their own wording what they associate with the elements that are presented to them (Goffin, 2002). This way their perception of the world around them is construed in their own "personal constructs" or measurement which reflect by which means they evaluate and judge the elements which represent the organization (Kelly, 2002). Instead of asking direct questions the interviewees, they are only confronted with elements that surround them as an employee of the investigated organization. The determination of elements has to follow some basic rules to ensure a holistic coverage of the research topics. The main criteria for choosing elements are if these are homogenous in the sense that they are from the same category, they should be representative to the topic investigated and unambiguous to the interviewee (Easterby-Smith et al., 1996). Wright and Lam propose in addition the use of more heterogeneous elements that signify a meaningful representation of the domain of interest (Wright and Lam, 2002). The following 27 elements were used to represent the organization and are designed to develop constructs in association with the investigated topics (Table 1).

The 27 elements are clustered into 3 main topics. It becomes evident that CS is not directly included in these clusters. This was done on purpose as some obvious elements may directly trigger thoughts of sustainability, which would have resulted in falsified results. The inductive approach of repertory grid still allowed the interviewees to state CS related constructs whilst not bringing up thoughts that they do not use in the context of judging the organization they are working for. 
Table 1

All 27 applied elements

\begin{tabular}{|c|c|c|}
\hline \multicolumn{3}{|l|}{ All elements } \\
\hline $\begin{array}{l}\text { The organization } \& \\
\text { market }\end{array}$ & Leadership \& Motivation & $\begin{array}{l}\text { Quality and internal } \\
\text { processes }\end{array}$ \\
\hline $\begin{array}{l}\text { The company as it used } \\
\text { to be }\end{array}$ & Myself today & HR \\
\hline The company today & My direct manager & Logistics/Warehouse \\
\hline $\begin{array}{l}\text { The company in } 2.5 \\
\text { years }\end{array}$ & $\begin{array}{l}\text { The company without } \\
\text { leadership }\end{array}$ & Sales Department \\
\hline The ideal company & Ideal leadership & $\begin{array}{l}\text { Product management / } \\
\text { purchase }\end{array}$ \\
\hline A negative company & Leadership culture & IT \\
\hline The companies brand & Myself as a manager & Marketing \\
\hline The market in the future & CEO 1 & Employee culture \\
\hline $\begin{array}{l}\text { An unpleasant } \\
\text { competitor }\end{array}$ & CEO 2 & Quality principle \\
\hline A meaningful company & A highly motivated person & An efficient process \\
\hline
\end{tabular}

The technique lets the interviewees compare a triad of 3 different elements of the set of 27 to construe their personal constructs. They were confronted with 3 elements and then asked, "in what way are two of these elements similar to each other and different from the third one". The elements surround the people during their work and are linked to company culture and leadership. This way these objects are part of the people's daily thoughts about their environment (Senior and Swailes, 2004). Elements like "quality principle" or "an efficient process" support creative thinking to ideally elicit a diverse number of qualitatively distinguishable metaphors that describe the corporate culture. The comparison method chosen is "triad oppositional" (Easterby- Smith et al., 1996). Kelly proclaimed that we analyse and describe our world by likenesses and differences of constructs. This bipolarity of personal constructs allows the design of repertory grids (Fransella, 2003). The interviewees state a contrary one to their originally created construct. As an evaluation method a tetrapolar field was chosen, to enable a divers set of possible evaluations (Senior and Swailes, 2004). This process was repeated until no further constructs were elicited.

Within the above-mentioned set of elements, the following elements and coordinates can be put into the context of corporate sustainability as they potentially lead to thoughts about the ecological footprint of the company or the quality of its products (Table 2).

Especially "A meaningful company" and "The market in the future" have the potential of evoking constructs that can be directly associated with corporate sustainability. This way their perception of the world around them is translated into personal constructs which reflect by which means they evaluate and judge the elements that are presented to them (Kelly, 2002). The constructs consist of the 
natural wording by the interviewed people based on the sum of their experiences. This way probands do not answer to questions and factors that they have not thought about before which case could it be when asking them how relevant they see for example leadership commitment in the context of corporate sustainability.

\section{Table 2}

\section{Coordinates of the main CS relevant element}

\begin{tabular}{|c|l|r|r|r|}
\hline No & \multicolumn{1}{|c|}{ Element } & $\mathbf{x}$ & $\mathbf{y}$ & $\mathbf{z}$ \\
\hline 1 & The company today & -7.59 & 20.68 & 12.30 \\
\hline 2 & Ideal leadership & 27.92 & -8.85 & 1.02 \\
\hline 3 & A meaningful company & 28.22 & -9.00 & 0.08 \\
\hline 4 & Leadership culture & 1.71 & 17.47 & 10.32 \\
\hline 5 & Employee culture & -5.80 & 10.96 & 11.73 \\
\hline 6 & The market in the future & 21.80 & -9.81 & -0.89 \\
\hline 7 & A negative company & -37.01 & 8.34 & -3.86 \\
\hline 8 & The companies brand & 11.60 & 8.67 & 9.81 \\
\hline 9 & The ideal company & 32.08 & -9.99 & 0.80 \\
\hline
\end{tabular}

The collected repertory grid data was analysed with a specialized software that uses generalized Procrustes analysis (GPA) to determine the unique coordinates of each construct and element. GPA allows to analyse and visualize three dimensional data matrices (Mak et al., 2013). The analysis indicates how the derived constructs are grouped together and in which relation they stand to each other. The software allows to determine the distances between the ranked elements and statistical indicators are produced to show the likelihood of constructs appearing next to each other by coincidence (Senior and Swailes, 2004; Tomic et al., 2015). The system clusters them automatically in dependence on their alignment towards each other. The interviews were carried out in the time frame from November 2018 to April 2019.

The elicitation of the above mentioned elements does not allow to predict any derived constructs but the context determines that topic related constructs are created (Fransella, 2003). The reviewed literature suggests that corporate sustainability is a relevant and important topic within business strategy and leadership to ensure the employees' commitment and retention (Engert and Baumgartner, 2016). Especially confronting employees, the CEOs and all corporate managers with the element's quality principle and their perception of their market and company in the future alongside with their perception of the brand leads to the following three hypotheses: $H_{1}$ : The repertory grid analysis allows to draw a picture of the status quo of Corporate Sustainability of an organization

$\mathrm{H}_{2}$ : The personal constructs reassure the relevance of sustainability in business operations and strategy

$H_{3}$ : Leadership has a direct impact on the CS status of an organization 


\section{RESULTS AND DISCUSSION}

Each repertory grid structured interview compiled in average 12 personal constructs related to the company's culture, strategy and sustainability status. All 782 constructs were dissected by generalized Procrustes analysis (GPA) which produces a three dimensional cognitive space of all constructs and elements (Tomic et al., 2015). This enables to draw conclusions about the semantic corridors, distances between the elements and the association of the probands with their company culture and the status of corporate sustainability. The following table lists all CS related constructs including the GPA produced unique coordinates (Table 3).

Table 3

\section{Coordinates of $\mathrm{CS}$ related personal constructs}

\begin{tabular}{|c|c|c|c|c|}
\hline No & Element & $\mathbf{x}$ & $\mathbf{y}$ & $\mathbf{z}$ \\
\hline \multicolumn{5}{|c|}{ Profit before quality } \\
\hline 1 & Profit before Quality & -9.34 & 31.60 & 11.22 \\
\hline 2 & Focus on profit and sales & -10.95 & 15.62 & 32.45 \\
\hline 3 & Sales-driven & -8.22 & 14.91 & 29.42 \\
\hline 4 & $\begin{array}{l}\text { Follow-up costs for new low-cost providers are not } \\
\text { taken into account }\end{array}$ & -25.25 & 28.62 & -5.84 \\
\hline 5 & Damaged reputation due to poor quality & -38.48 & 10.13 & -9.46 \\
\hline 6 & Price is more important than quality & -22.65 & 27.80 & -14.30 \\
\hline 7 & React only to complaints (not proactively) & -30.10 & 20.81 & -4.45 \\
\hline 8 & Set price before quality, no quality control & -32.46 & 13.35 & 21.67 \\
\hline 9 & Driven by the market & -19.32 & 26.59 & 21.52 \\
\hline 10 & Pure profit-seeking (antisocial business conduct) & -10.68 & 31.38 & -6.37 \\
\hline 11 & Set to old values & -28.52 & 12.75 & 14.68 \\
\hline 12 & Pollution of the environment & -30.56 & 22.71 & -2.69 \\
\hline \multicolumn{5}{|c|}{ Ecology } \\
\hline 13 & Sustainability (not only profit optimization) & 14.95 & -34.72 & 4.23 \\
\hline 14 & $\begin{array}{l}\text { Increase quality, detect product defects early and act } \\
\text { accordingly }\end{array}$ & 31.51 & -8.28 & -8.68 \\
\hline 15 & Ecological sustainability & 6.91 & -34.94 & -10.43 \\
\hline 16 & Clear quality standards (or management) & 31.38 & -15.84 & -13.49 \\
\hline \multicolumn{5}{|c|}{ Company and brand reputation } \\
\hline 17 & $\begin{array}{l}\text { Try to establish the company as a brand (not only } \\
\text { company logo) }\end{array}$ & 35.92 & 10.76 & 6.40 \\
\hline 18 & Ideals and values are pursued & 35.06 & 7.13 & 1.10 \\
\hline 19 & Stand out from the crowd in terms of quality & 30.27 & 9.79 & 12.35 \\
\hline 20 & Good working environment (team spirit/success) & 31.56 & 11.79 & 12.36 \\
\hline 21 & Improve market reputation and perception & 24.22 & -2.26 & 26.01 \\
\hline 22 & High willingness to perform through social activities & 36.39 & 8.01 & -1.97 \\
\hline
\end{tabular}


An example construct is "pollution of the environment" on which for example the elements "The company today", "the brand" or "our company culture" are rated on a scale from 0 to 100 . The personal constructs of the interviews were people qualitatively reviewed to assess their linkage to sustainability. One analysis that was done is to check which constructs come up with a relevance of: "The market in the future" (grading $>80 \%$ ) and "the brand of the company" (grading $>80 \%$ ). 97 constructs out of 782 fulfil these criteria whilst 22 can be related to corporate sustainability. Hence $2,8 \%$ percent of personal constructs are sustainability related issues. They were clustered by the location in the three-dimensional grid as shown in table 1 and visualized in figure 1 . The utilized repertory grid tool allows to draw a three-dimensional space of the coordinates of these elements and constructs. This way the semantic corridors become visible. In addition, the status quo of the organization with regards to the above-mentioned CS can be visualized. Referring to $H_{1}$ : The repertory grid analysis allows to draw a picture of the status quo of Corporate Sustainability of an organization it can be concluded that a repertory grid analysis on the basis of the PSP by Kelly is an adequate possibility to visualize and analyse the CS estate of a company. It can be critically discussed whether a different design of elements would have generated a different set of results. Here a fine line between giving room for CS related thoughts and triggering them by obviously related elements has to be drawn. The following picture visualizes the CS status of the organization in 2019 (Figure 1).

\section{Figure 1}

\section{Three-dimensional visualization of the repertory grid results}

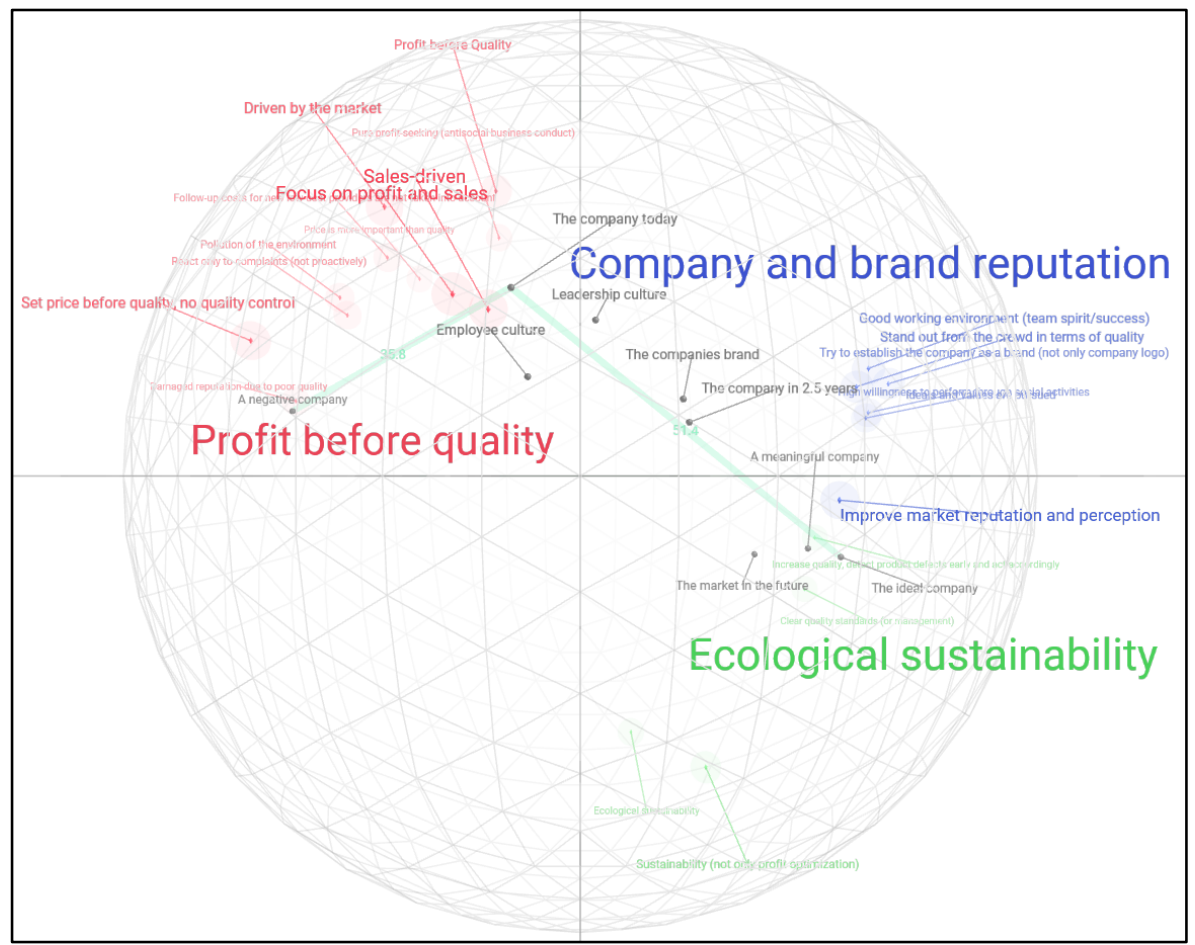


Centrically aligned elements are coordinated in a three-dimensional space. The genuine constructs are grouped into coloured clusters. The headings were chosen by the researcher to allow a prompt comprehension of the three main semantic corridors. The CS status of the organization is described by the location of the element "The company today" which is allocated in the semantic corridor summarized by "Profit before quality", as most constructs relate to this topic. In contrast, the elements "A meaningful company" and the "The market in the future" are located in the corridor that is headed by "Ecological sustainability". So even the interviewees do not rate their own organization highly for these constructs, they associate the construct being relevant in their market of the future. The low percentage of directly CS relevant constructs though leads to the conclusion that at a current stage it is not a relevant topic in judging the organization. In consequence $\mathrm{H}_{2}$ : The personal constructs reassure the relevance of sustainability in business operations and strategy can be rejected for the underlying research case as only $2,8 \%$ of constructs are CS relevant according to Lozano's criteria (Lozano, 2013). For this, constructs were reviewed that were highly relevant for the companies' brand and the market in the future.

To assess whether leadership has a direct impact on the CS status of an organization, the data set allows a possibility of measurement. The congruence of the semantic corridor of the "Leadership culture", "Employee culture" and "The company today" can indicate their degree of correlation. The following image (Figure 2) highlights all constructs and elements that lie in a corridor of 45 degrees centred around the element "The company today".

\section{Figure 2}

\section{Semantic corridor of $45^{\circ}$ for "The company today"}

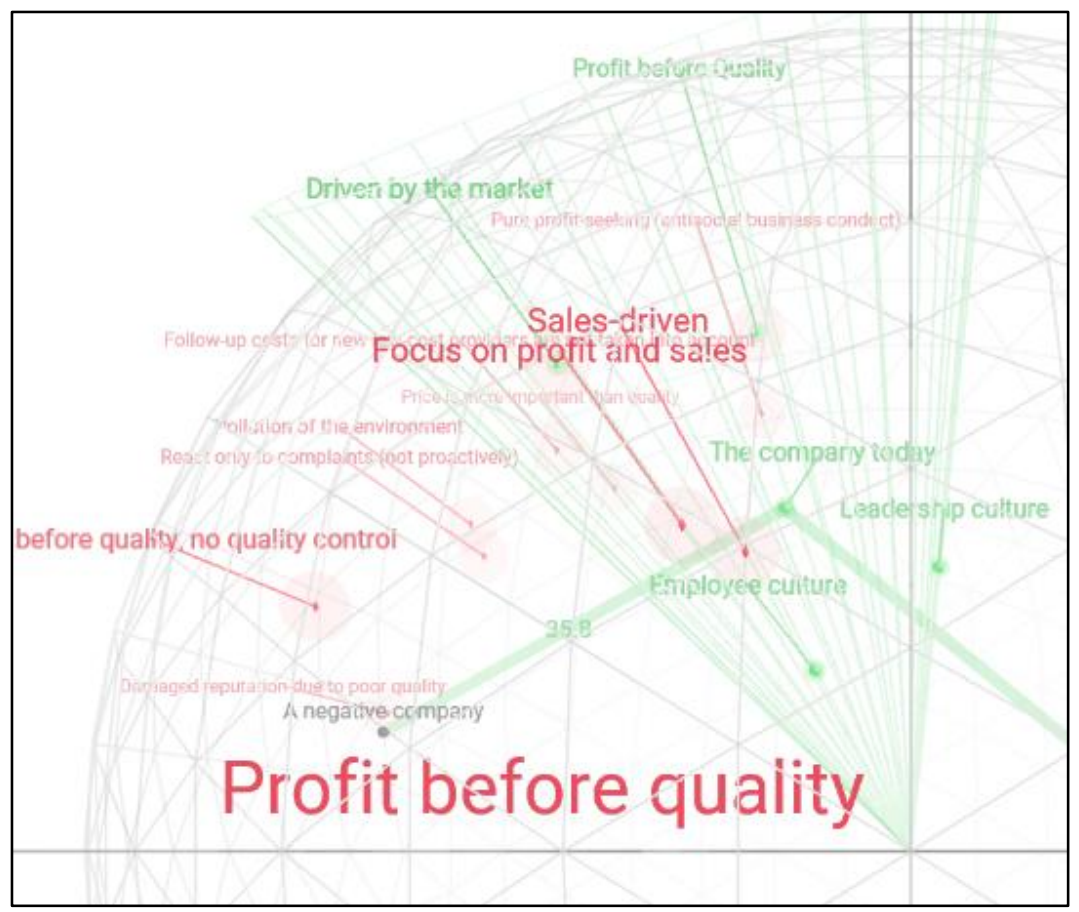


As all three elements lie relatively close to each other in the three-dimensional cognitive space, it can be concluded that $H_{3}$ : Leadership has a direct impact on the CS status of an organization. The two closest constructs "Driven by the market" and "Profit before quality" reassure $\mathrm{H}_{1}$ as they stand representative for the other constructs of this corridor. Critically it must be stated that the deficiency of CS implementation of this organization derives from a small basis for proving hypothesis three. In this context a time dependent analysis would produce more significant results.

\section{CONCLUSION}

Only in 2,8\% of the personal constructs of the interviewed people are linked to corporate sustainability relevant topics like societal influence, environmental impact or organizational culture (Rego et al., 2015). This finding leads to a rejection of hypothesis 2 that the personal constructs of the investigated research subject reassure the relevance of sustainability in business operations and strategy. Neither within the minds of the leaders nor of the employees the above-mentioned topics play an important role. Critically it has to be stated that this research was linked to one corporation, hence it is not possible to draw economy- wide conclusions. Further research should be done if the number of sustainability constructs of the general managers and leaders of the company coincide with the relevance and number of sustainability constructs of employees. It means if the leaders consider CS as an important subject, this rubs off on the staff members of their department. That way it can be measured how effectively the leadership incorporates sustainability into the business.

Positively it can be concluded that applying Kelly's personal construct psychology with the help of repertory grid structured interviews is an adequate possibility to draw a picture of the CS status of an organization. For further research it would be interesting what kind of results are elicited when applying the methodology to another organization or the same organization after several years.

Finally, it can be concluded that corporate sustainability is directly associated with leadership and company culture. As CS is still not strongly implemented in the investigated organization, the basis for this conclusion is not very strong. As a result of this research the organization implemented a strategy definition progress and integrated for the first-time corporate sustainability into its mission statement. To evaluate the effectiveness of the implementation of different approaches to implement CS into operations it would be highly interesting to carry out the same research in 2,5 to 3 years after the first conduct. This may produce a valuable data set on how effective different CS implementation processes are and how strongly they depend on leadership involvement.

\section{ACKNOWLEDGEMENT}

The publication of this paper is supported by the EFOP-3.6.2-16-2017-00018 "Produce together with the nature - agroforestry as a new outbreaking possibility" project. 


\section{REFERENCES}

Ameer, R., Othman, R. (2011): Sustainability Practices and Corporate Financial Performance: A Study Based on the Top Global Corporations. In: Journal of Business Ethics, 108. 1. 61-79. p. doi: 10.1007/s10551-011-1063-y

Aras, G., Crowther, D. (2008): Corporate Sustainability Reporting: A Study in Disingenuity? In: Journal of Business Ethics, 87. S1. 279-288. p. doi: 10.1007/s10551-008-9806-0

Ashrafi, M., Adams, M., Walker, T.R., Magnan, G. (2018): "How corporate social responsibility can be integrated into corporate sustainability: a theoretical review of their relationships." In: International Journal of Sustainable Development \& World Ecology, 25. 8. 672-682. p. doi: 10.1080/13504509.2018.1471628

Bonn, I., Fisher, J. (2011): Sustainability: the missing ingredient in strategy. In: Journal of Business Strategy, 32. 1. 5-14. p. doi: 10.1108/02756661111100274

Cassell, C., Close, P., Duberley, J., Johnson, P. (2000): Surfacing embedded assumptions: Using repertory grid methodology to facilitate organizational change. In: European Journal of Work and Organizational Psychology, 9. 4. 561-573. p. doi: https://doi.org/10.1080/13594320050203139

Dunphy, D.C., Griffith A.; Benn, S. (2007): Organizational change for corporate sustainability. A guide for leaders and change agents of the future. London: Routledge, 346 p. ISBN: 0415393299

Dyllick, T., Hockerts, K. (2002): Beyond the business case for corporate sustainability. In: Business Strategy and the Environment, 11. 2. 130-141. p. doi: 10.1002/bse. 323

Easterby-Smith, M., Thorpe, R., Holman, D. (1996): Using repertory grids in management. In: Journal of European Industrial Training, 20. 3. 3-30. p. doi: 10.1108/03090599610114138

Engert, S., Baumgartner, R.J. (2016): Corporate sustainability strategy - bridging the gap between formulation and implementation. In: Journal of Cleaner Production, 113. 822-834. p. doi: 10.1016/j.jclepro.2015.11.094

Engert, S., Rauter, R., Baumgartner, R.J. (2016): Exploring the integration of corporate sustainability into strategic management: a literature review. In: Journal of Cleaner Production, 112. 2833-2850. p. doi: 10.1016/j.jclepro.2015.08.031

Epstein, M. J., Roy, M.-J. (2001): Sustainability in Action: Identifying and Measuring the Key Performance Drivers. In: Long Range Planning, 34. 5. 585-604. p. doi: 10.1016/s0024-6301(01)00084-x

Eweje, G. (2011): A Shift in corporate practice? Facilitating sustainability strategy in companies. In: Corporate Social Responsibility and Environmental Management, 18. 3. 125-136. p. doi: 10.1002/csr.268

Frankental, P. (2001): Corporate social responsibility - a PR invention? In: Corporate Communications: An International Journal, 6. 1. 18-23. p. doi: $10.1108 / 13563280110381170$

Fransella, F. (ed.) (2003): International Handbook of Personal Construct Psychology. Chichester: Wiley, 528 p. ISBN-10: 0470847271 
Fransella, F., Bell, R., Bannister, D. (2003): A Manual for Repertory Grid Technique. Chichester: Wiley, 280 p. ISBN: 978-0-470-85490-7

Goffin, K. (2002): Repertory Grid Technique. In: Partington, D. (ed.): Essential Skills for Management Research, 199-225. p. doi: 10.4135/9781848605305.n11

Hahn, R. (2012): ISO 26000 and the Standardization of Strategic Management Processes for Sustainability and Corporate Social Responsibility. In: Business Strategy and the Environment, 22. 7. 442-455. p. doi: 10.1002/bse.1751

Hahn, T., Figge, F. (2011): Beyond the Bounded Instrumentality in Current Corporate Sustainability Research: Toward an Inclusive Notion of Profitability. In: Journal of Business Ethics, 104. 3. 325-345. p. doi: 10.1007/s10551-0110911-0

Hahn, T., Figge, F., Pinkse, J., Preuss, L. (2017): A Paradox Perspective on Corporate Sustainability: Descriptive, Instrumental, and Normative Aspects. In: Journal of Business Ethics, 148. 2. 235-248. p. doi: 10.1007/s10551-017-3587-2

Kelly, G.A. (1955): The Psychology of Personal Constructs. New York: Norton

Klettner, A., Clarke, T., Boersma, M. (2013): The Governance of Corporate Sustainability: Empirical Insights into the Development, Leadership and Implementation of Responsible Business Strategy. In: Journal of Business Ethics, 122. 1. 145-165. p. doi: 10.1007/s10551-013-1750-y

Lozano, R. (2012): Towards better embedding sustainability into companies' systems: an analysis of voluntary corporate initiatives. In: Journal of Cleaner Production, 25. 14-26. p. doi: 10.1016/j.jclepro.2011.11.060

Lozano, R. (2013): A Holistic Perspective on Corporate Sustainability Drivers. In: Corporate Social Responsibility and Environmental Management, 22. 1. 32-44. p. doi: $10.1002 / \operatorname{csr} .1325$

Rego, A., Cunha, M.P.e., Polónia, D. (2015): Corporate Sustainability: A View From the Top. In: Journal of Business Ethics, 143. 1. 133-157. p. doi: 10.1007/s10551015-2760-8

Robertson, A. (2003): Making Sense of the 'Group Mind'. In: Fransella F. (ed.): International handbook of personal construct psychology. Chichester: Wiley 339-348. p. doi: 10.1002/0470013370.ch34

Schaltegger, S., Lüdeke-Freund, F. (2012): The "Business Case for Sustainability" Concept: A Short Introduction. Lüneburg. Centre for Sustainability Management (CSM), 14. p. ISBN 978-3-942638-22-7

Sen, S., Bhattacharya, C.B. (2001): Does Doing Good Always Lead to Doing Better? Consumer Reactions to Corporate Social Responsibility. In: Journal of Marketing Research, 38. 2. 225-243. p. doi: 10.1509/jmkr.38.2.225.18838

Tomic, O., Berget, I., Næs, T. (2015): A comparison of generalised procrustes analysis and multiple factor analysis for projective mapping data. In: Food Quality and Preference, 43. 34-46. p. doi: 10.1016/j.foodqual.2015.02.004

Wright, R. P., Lam, S. S. K. (2002).: Comparing Apples with Apples: The Importance of Element Wording in Grid Applications. In: Journal of Constructivist Psychology, 15. 2. 109-119. p. doi: 10.1080/10720530252808692 
Correspondent author:

\section{Henning BUNDTZEN}

Kaposvár University

Doctoral School in Management and Organizational Sciences

H-7400 Kaposvár, Guba Sándor u. 40.

e-mail: henning.bundtzen@outlook.de 